\title{
Standards-Based Specifications Grading in a Hybrid Course
}

\section{Dr. Julie Mendez, Indiana University-Purdue University Columbus}

Julie Mendez is a Clinical Assistant Professor in the Division of Mechanical Engineering at Indiana University-Purdue University Columbus. Her interests include active learning, online course development, and standards-based grading. 


\title{
Standards-Based Specifications Grading in a Hybrid Course
}

\begin{abstract}
Standards-based grading is being used increasingly in engineering courses in place of a traditional points-based grading system. Benefits of standards-based grading include clearly matching course assessments to the learning objectives and putting more focus on learning instead of grades. In specifications grading, students are given detailed requirements with all assignments, which are graded pass/fail. The course grade is based on the number of assignments successfully completed. As more undergraduate courses are offered in online or hybrid formats, there is little documentation of the use of standards-based grading or specifications grading in these course delivery methods in engineering. This work describes the implementation of standards-based specifications grading (SBSG) in a hybrid (approximately 80\% online) undergraduate thermodynamics course.
\end{abstract}

\section{Introduction}

Standards-based grading is being used more frequently in engineering courses [1], [2]. In a traditional grading scheme, the course grade is determined based on scores of individual assignments and exams, but in standards-based grading, the course grade is based on how many standards, or learning outcomes, the student has mastered. In standards-based grading, the learning outcomes are clear to the students and each assignment is aligned with one or more learning outcomes.

Specifications grading [3] bears some similarity to contract grading [4]; however, instead of creating an individual contract for each student or having students commit to a particular grade at the start of the course, students are given specifications, or detailed requirements for successful completion, for each assignment or assessment. The work is then graded on a pass/fail basis. Higher course grades require passing a greater number of assignments or passing more challenging assignments. Students are typically allowed to revise and resubmit a small number of assignments that failed to meet the specifications. Some higher education instructors [5], [6] have preferred a four-level rubric [7] for some assessments instead of pass/fail. Others have given students an unlimited number of revisions of some assessments [6].

While specifications grading is being used in a variety of disciplines [8]-[10], and there are an increasing number of online or hybrid engineering courses [11]-[19], there is little work on specifications grading used in online engineering courses. This paper will describe the implementation of standards-based specifications grading (SBSG) in a sophomore-level thermodynamics course, offered in a hybrid (approximately 80\% online) format, in a mechanical engineering curriculum.

\section{Description of Course}

The course was offered in a hybrid format for the first time in the 2017 fall semester. The course was taught in a traditional in-person format in the 2016 fall semester by the same instructor using SBSG. The original plan for the hybrid course involved a face-to-face meeting approximately 
once every two weeks, for approximately two hours (one lecture hour and one recitation hour). However, the instructor found out a few months before the start of the course that she would be out of the country for most of the semester the hybrid course would be implemented. Therefore, some of the planned face-to-face meetings were replaced with proctored in-class quizzes during 4 class sessions and more content was placed online. The students met with the instructor in person during the last two weeks of the semester.

The course was delivered asynchronously through the Canvas learning management system [20] with Fundamentals of Engineering Thermodynamics by Moran et al. [21] as the required textbook and major source of course content. The course material was organized into 9 modules, with each module taking one to two weeks. The modules and topics within each module are listed in Table 1. Instruction for all but the last module was completely online, and the last module was a combination of online and in-person.

Table 1: Course Organization

\begin{tabular}{|l|l|l|l|}
\hline Module & Week & Topic & Quiz Mode \\
\hline Introduction & 1 & Closed System vs. Control Volume & Online \\
\cline { 3 - 4 } & & Property, State, Process & Online \\
\hline Analyzing Closed Systems & $2-3$ & Expansion/Compression Work & In-person \\
\cline { 3 - 4 } & & Closed System Energy Balance & In-person \\
\hline Retrieving Property Data & $4-5$ & Property Data & Online \\
\cline { 3 - 4 } & & Ideal Gas Law & Online \\
\hline Analyzing Control Volumes & \multirow{2}{*}{$6-7$} & Steady-State Control Volume & In-person \\
\cline { 3 - 4 } & & Unsteady-State Control Volume & In-person \\
\hline Thermodynamic Cycles & \multirow{2}{*}{$8-9$} & Cycle Performance & Online \\
\cline { 3 - 4 } & & Carnot Cycle & Online \\
\hline Entropy Balance & 10 & Entropy Balance & In-person \\
\hline Vapor Power Systems & 11 & Vapor Power System & In-person \\
\hline Gas Power Systems & $12-14$ & Otto, Diesel, Dual Cycles & In-person \\
\cline { 3 - 4 } & & Gas Turbine Power Cycle & In-person \\
\hline Refrigeration \& Heat Pump \\
Systems & $15-16$ & Refrigeration \& Heat Pump Cycles & In-person \\
\hline
\end{tabular}

The key topics of the course were split into 15 statements, each written in terms of what the student should be able to do. An example of these statements is "Analyze a closed system by applying energy balances and correctly applying sign conventions for work and heat transfer". The full list is given in Appendix A. Each statement corresponded to one quiz. The quiz mode for each course topic is given in Table 1.

Six quizzes were taken online. In each quiz attempt, a question was pulled from a question bank. The student completed the problem during the allotted time (up to 60 minutes for a more complex topic) and submitted their solution, typically by uploading a scanned copy of their handwritten work. After receiving feedback from the instructor, the student could attempt the 
quiz again. This cycle could be repeated as many times as the student wished, until they were happy with the quiz score or until the end of the course.

The other nine quizzes were taken in class, either in the presence of a proctor or the course instructor. Students could retry in-class quizzes, with a different question on the same topic, during a later class period or by scheduling an appointment with the instructor outside of class time. Students could retry a quiz as often as they liked until the end of the course. Due to the instructor being away from campus most of the semester, quiz retry appointments were only allowed during the last three weeks of the semester.

A design project [22] was assigned to groups of 3 students. Group assignments were made by the instructor. Each student group completed a report and gave a brief in-class presentation about their design. After receiving feedback, students had the opportunity to revise and resubmit the report, and revise the presentation.

Quizzes and projects were graded using the four-level EMRN rubric [5], [6], based on the EMRF rubric [7]. Scores of "E" (excellent) and " $M$ " (meets expectations) were passing. Scores of "R" (needs revision) and "N" (not assessable) were not passing.

The course was structured in a flipped learning format, and students were expected to complete an assignment at the introduction of a new topic to prepare them for the online activities and the face-to-face class meetings. These Guided Practice assignments [23] typically involved reading assigned sections of the textbook, watching videos, and responding to questions. The instructor created some of these videos and used videos from other sources [24]. There were 14 of these assignments, typically one at the beginning of each week. An example of a Guided Practice assignment is given in Appendix B.

Participation assignments were an opportunity to practice each of the course topics. One category of these assignments was a discussion, where the class was divided into groups of 3-5 students, who completed an assigned problem using the discussion forum feature of the course management system. Another assignment type was a peer review activity, in which each student submitted their solution to an assigned problem. Each student who submitted a solution on time was assigned to review a solution submitted by another student and provide feedback anonymously. The last type of Participation assignment involved students answering short problems. The responses were automatically graded by the course management system, and students received feedback about the correct solution. There were 44 Participation assignments, typically 3 or 4 each week. There were fewer of these assignments during the last two weeks of the course when the students met face-to-face with the instructor.

Guided Practice and Participation assignments were graded either "Pass" or "No Pass". A "Pass" score was earned if the assignment was submitted no later than 24 hours after the due date and if each question or problem had a response that reflected the student's good-faith effort to be correct [25].

The final course grade was assigned based on how many assignments earned a passing score and how many "E" scores were earned on quizzes. Table 2 describes the requirements to earn a 
particular base letter grade (A, B, C, etc.). All requirements for a grade had to be met in order to earn that grade. A course grade of " $F$ " was earned if the requirements for a " $D$ " were not met. A grade checklist was also provided to students to help them track their progress.

Table 2: Course Grade Requirements

\begin{tabular}{|l|l|}
\hline $\begin{array}{l}\text { To earn } \\
\text { this grade: }\end{array}$ & Accomplish the following: \\
\hline A & $\begin{array}{l}\text { Earn passing scores on } 15 \text { quizzes, including at least 11 "E" scores, AND earn } \\
\text { passing scores on project report and presentation. }\end{array}$ \\
\hline B & $\begin{array}{l}\text { Earn passing scores on } 13 \text { quizzes, including at least } 7 \text { "E" scores, AND earn } \\
\text { passing scores on project report and presentation. }\end{array}$ \\
\hline C & $\begin{array}{l}\text { Earn passing scores on 11 quizzes (no "E" scores required), AND earn passing } \\
\text { scores on project report and presentation. }\end{array}$ \\
\hline D & Earn passing scores on 9 quizzes (no "E" scores required). \\
\hline
\end{tabular}

A "plus" was added to the base grade $(\mathrm{A}+, \mathrm{B}+$, etc. $)$ if a student earned "Pass" scores on at least 13 Guided Practice and at least 39 Participation assignments. A "minus" was added to the base grade (A-, B-, etc.) if a student earned "Pass" scores on fewer than 8 Guided Practice or on fewer than 25 Participation assignments.

One significant change in the course design from 2016 to 2017 was a change in the number of standards from 33 to 15 . Some standards were removed because they did not align with the course learning outcomes. One example of a standard that was removed is "Solve simple pressure measurement problems involving manometers and barometers". Some standards were combined. For example, the standard "Sketch schematic diagrams and accompanying $T-S$ diagrams of Rankine, reheat, and regenerative vapor power cycles" was incorporated into the standard "Apply conservation of mass and energy, the second law, and property data to determine power cycle performance".

Another major change was that some specific standards were required to be passed in order to earn a grade of " $C$ " or better in the 2016 course. This requirement was removed in the 2017 course.

\section{Student Performance}

All standards in the 2017 hybrid class (18 students) were also assessed in the 2016 traditional class (18 students). In the 2016 class, all quizzes took place during class time. In the 2017 class, nine quizzes occurred during class time, and six quizzes were administered online. The percentage of students who earned a passing score ("E" or "M") on each standard was compared for the two classes.

Figure 1 shows the percentage of students who earned a passing score on selected course assessments in the 2016 traditional class and the 2017 hybrid class. The nine topics presented here correspond to the nine proctored quizzes in the hybrid class. Four of the nine compared 
topics (closed system energy balance, steady-state control volume, entropy balance, and vapor power system) were required to be passed in the 2016 class to earn a grade of "C" or better.

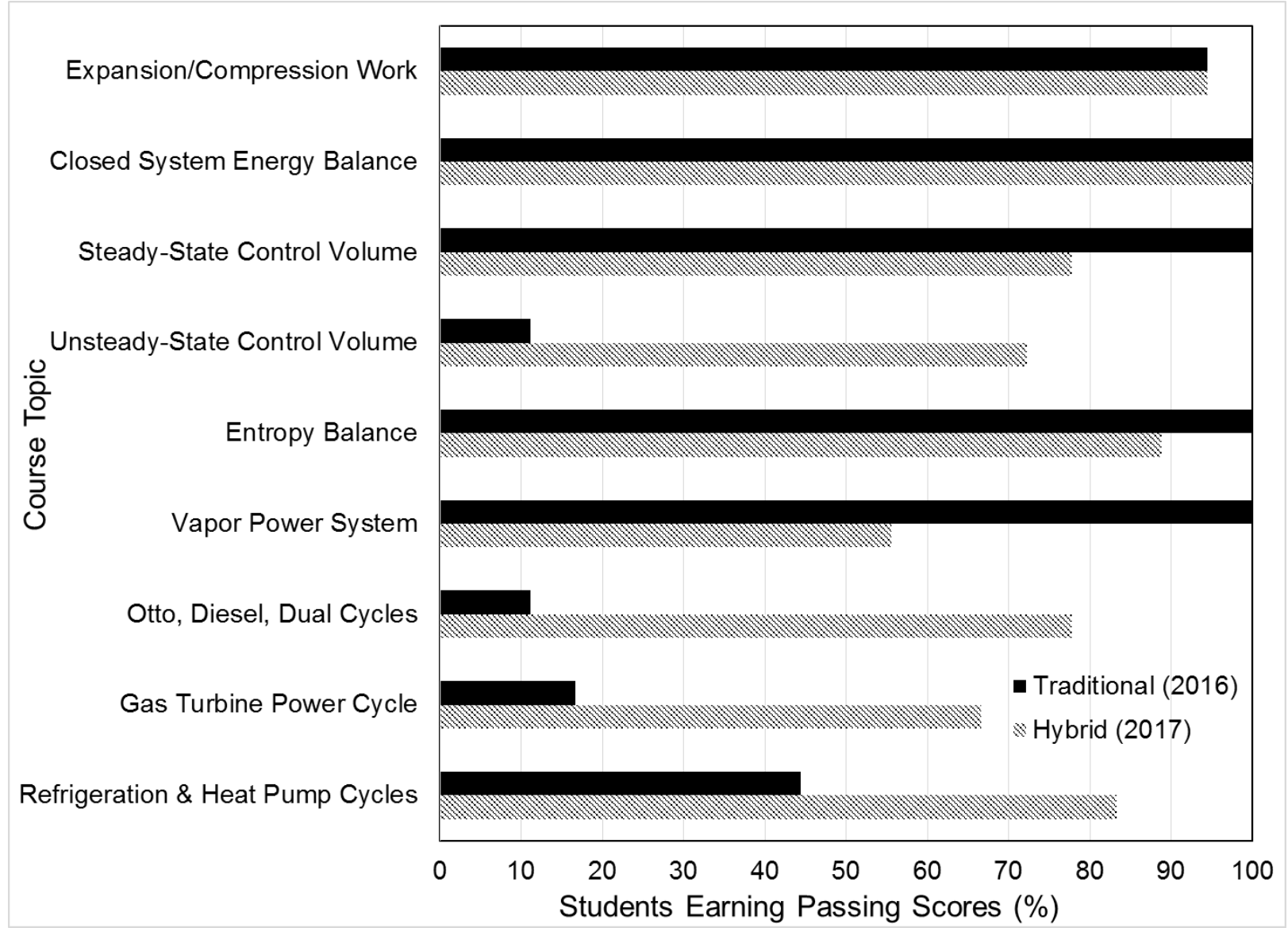

Figure 1. Student performance on course assessments in the traditional (solid bars) and hybrid (dashed bars) classes. In the hybrid class, these quizzes were proctored and took place in class.

Figure 2 shows the percentage of students who earned a passing score on selected course assessments in the 2016 traditional class and the 2017 hybrid class. The six topics presented here correspond to the six online quizzes in the hybrid class. Four of the six compared topics (closed system and control volume; property, state, process; property data; and cycle performance) were required to be passed in the 2016 class to earn a grade of " $C$ " or better.

Figure 3 shows the percentage of students who earned a passing score in the hybrid class after the first quiz attempt and after one or more retries. The nine topics presented here correspond to the nine proctored quizzes in the hybrid class. Two topics, expansion/compression work and closed system energy balance, had initial pass rates at or near $100 \%$. All other topics had initial pass rates below $80 \%$, including four topics with initial pass rates at or below $50 \%$ (steady-state control volume, unsteady-state control volume, vapor power system, and gas turbine power system). The topics with the largest percentage of students eventually passing a retry were steady-state control volume and unsteady-state control volume. 


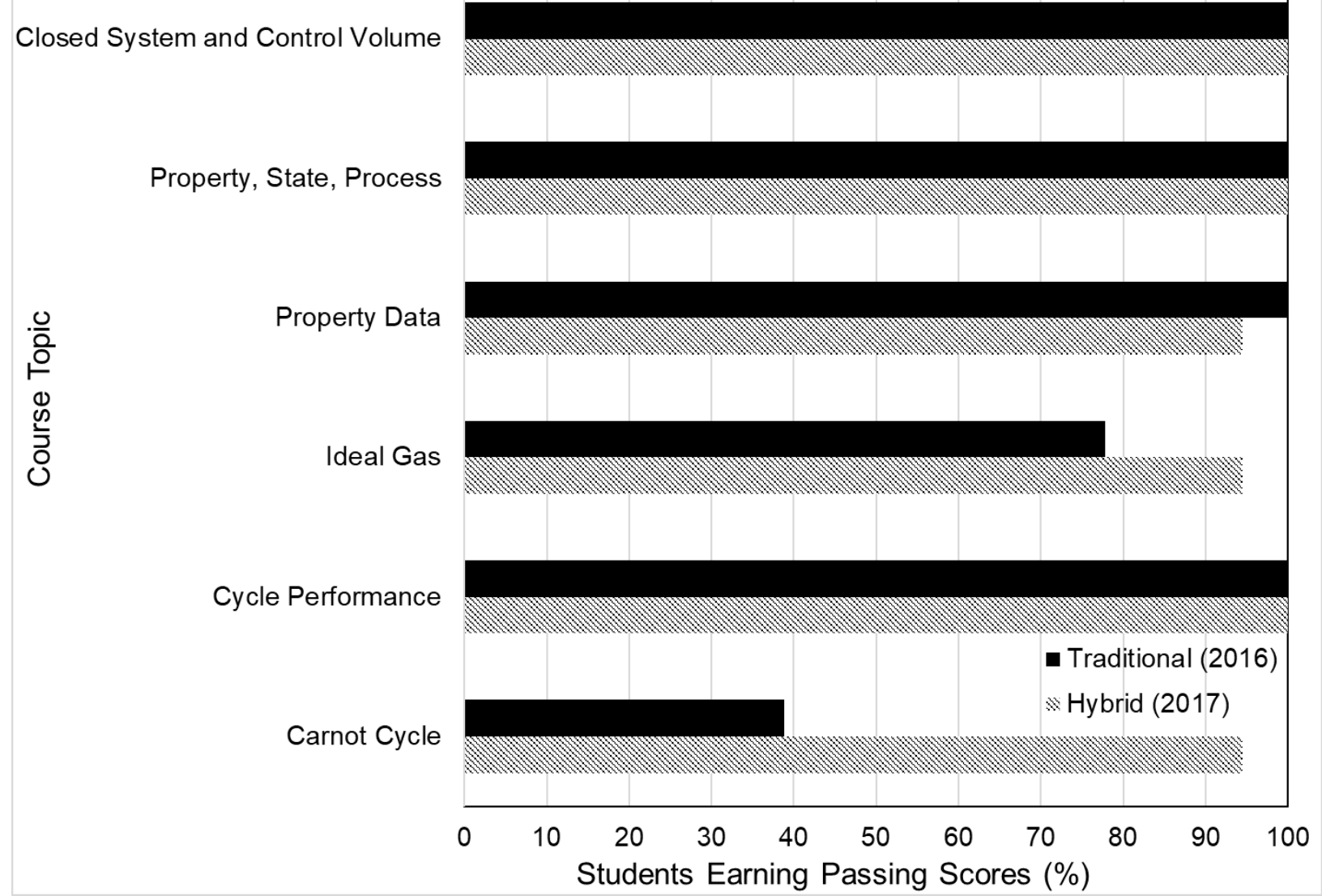

Figure 2. Student performance on course assessments in the traditional (solid bars) and hybrid (dashed bars) classes. In the hybrid class, these quizzes were administered online.

Figure 4 shows the percentage of students who earned a passing score in the hybrid class after the first quiz attempt and after one or more retries. The six topics presented here correspond to the six online quizzes in the hybrid class. Three topics (closed system and control volume; property, state, process; and cycle performance) had initial pass rates above $85 \%$. All other topics had initial pass rates above $50 \%$. Over $90 \%$ of the students had eventually passed each of these quizzes by the end of the course.

\section{Student Comments}

The students were not surveyed specifically about the grading system or their perception of the hybrid course format. General student feedback was collected in two forms: the university endof-semester course evaluation and a midterm feedback questionnaire. Both were anonymous.

Only 5 of the 18 students completed the midterm feedback questionnaire. No students commented specifically about the grading system, but one student liked the organization of the course. Three students noted difficulty with reading the textbook. One student thought there should be more examples. One student admitted having a difficult time learning online. 


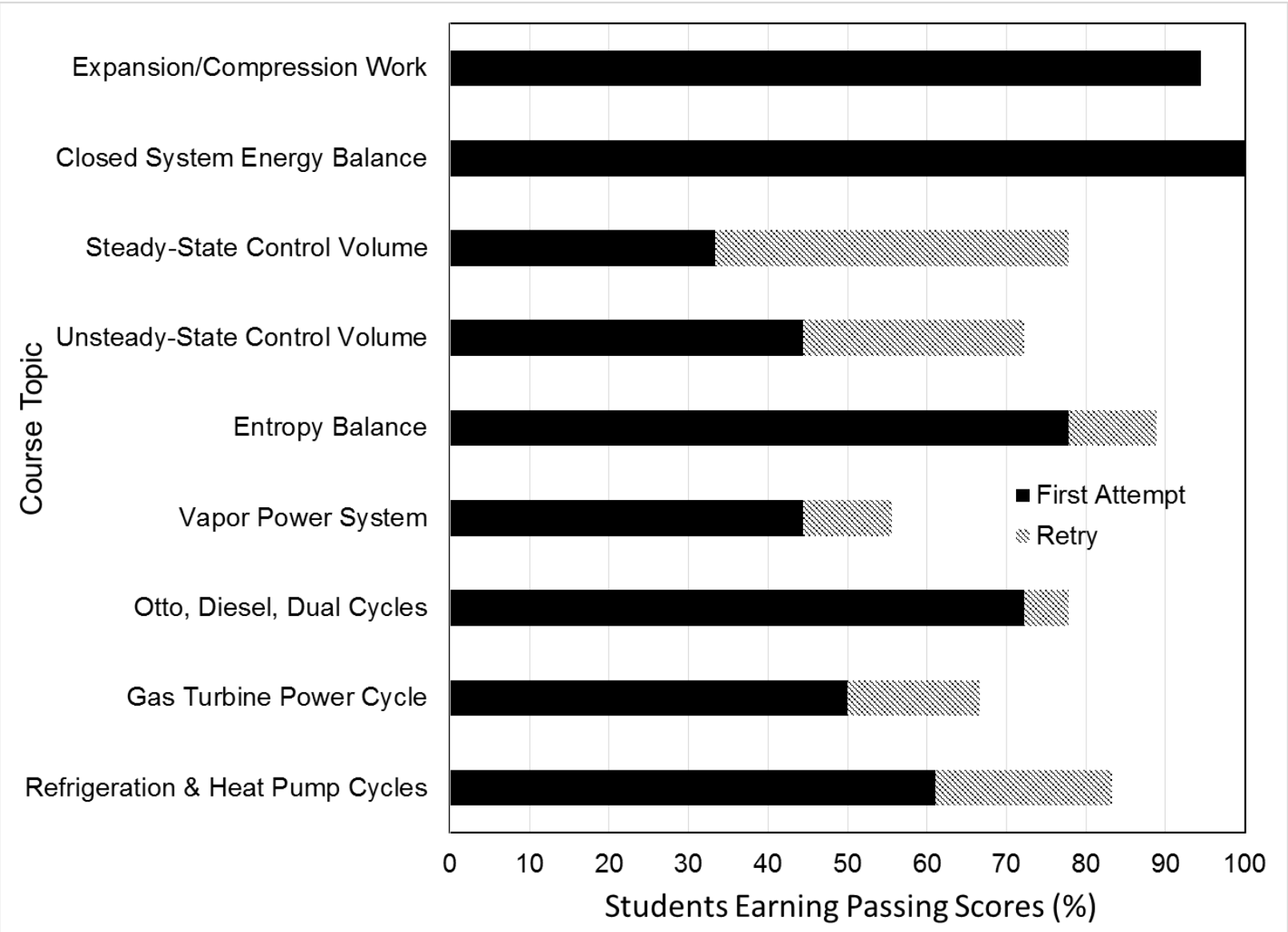

Figure 3. Student performance on course assessments in the hybrid class after the first attempt (solid bars) and after one or more retries (dashed bars).

Eight out of the 18 students completed the course evaluation at the end of the semester. Only 6 comments to each of the open-response questions were submitted. Again, no students commented specifically about the grading system, but one student made a positive comment about the organization of the course. When asked what changes the instructor can make, 3 students noted that they wished the course was not online, and 3 students requested more lectures or examples. When asked for additional comments, 2 students stated they would prefer that the class not be online, 2 students expressed having difficulties keeping up with the material, and 2 students admitted difficulties with reading the textbook.

\section{Conclusion}

This was the second time the instructor used SBSG in this course and the first time in the hybrid format. In the first time using SBSG, there were 33 key course topics or quizzes. In a 15-week course, this was more than 2 topics per week. The 15 topics assessed in the hybrid course was more manageable for the instructor and students. It is recommended to focus on only one topic or standard most weeks. 


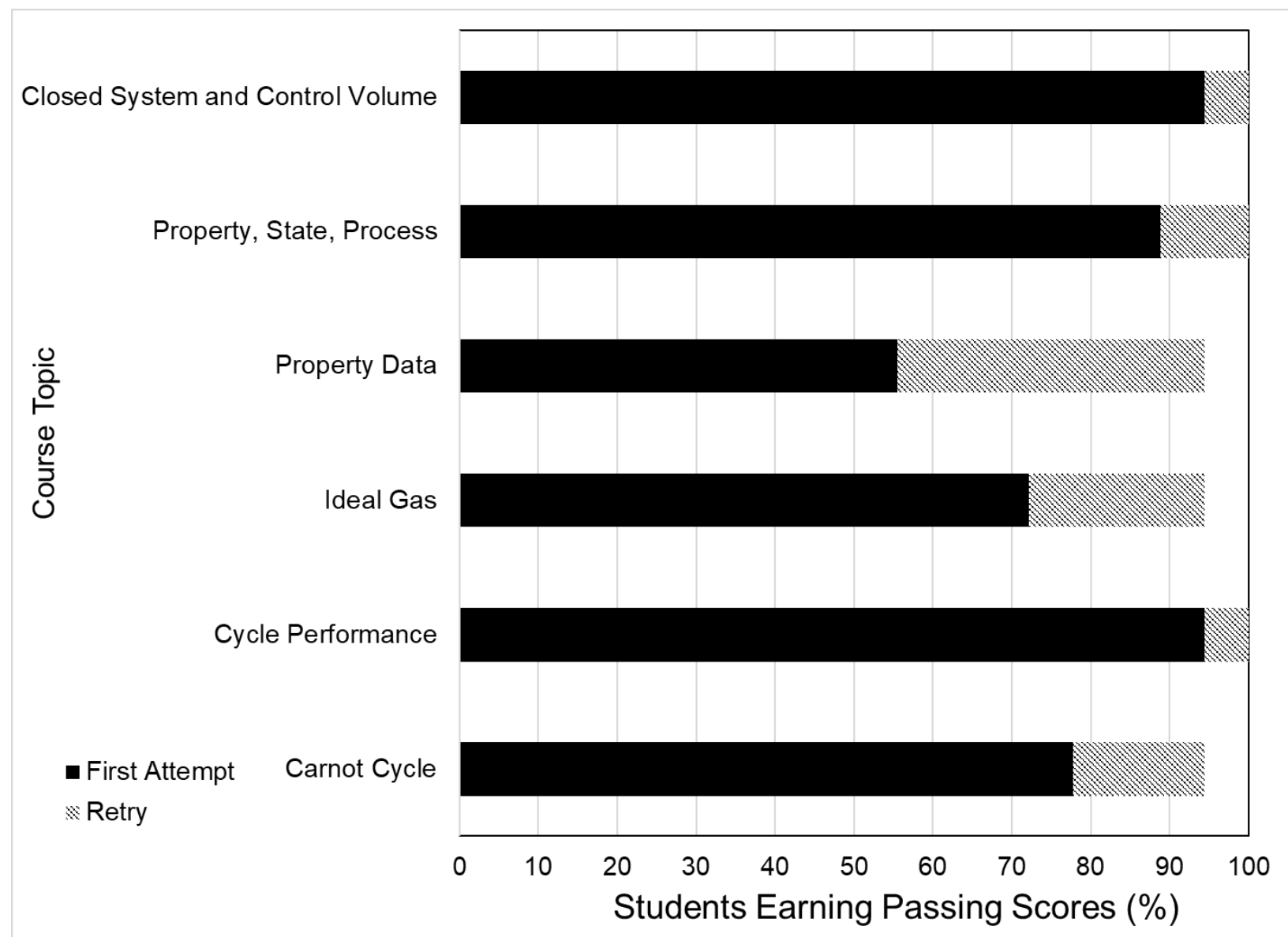

Figure 4. Student performance on course assessments in the hybrid class after the first attempt (solid bars) and after one or more retries (dashed bars).

In the 2016 course, 18 of the 33 quizzes required a passing score for the student to earn a course grade of "C" or better. This resulted in all students passing those 18 topics. However, some other topics had pass rates below 20\%, including topics introduced during the later part of the course, such as Otto, Diesel, and dual cycles. In the 2017 course, passing scores on specific quizzes were not required for any course grade. This resulted in higher pass rates on topics covered toward the end of the course.

Students were able to perform better on course assessments due to having opportunities for reassessment. There were a small number of students involved in this course and a low response rate on the student surveys. Additional research is needed to determine student perceptions of SBSG in this type of course. Future course preparation will involve revising portions of the course where quiz pass rates were low. Future work will involve surveying students on their perceptions of standards-based specifications grading to gain meaningful feedback due to the low course evaluation response rate.

\section{Appendix A: List of Quiz Topics}

1A. Distinguish between a closed system and a control volume (open system). 
1B. Explain the following concepts in your own words: property, state, and process.

2A. Evaluate expansion or compression work.

2B. Analyze a closed system by applying energy balances and correctly applying sign conventions for work and heat transfer.

3A. Retrieve property data such as specific volume and specific enthalpy from tables, using linear interpolation when necessary.

3B. Apply the ideal gas model for thermodynamic analysis.

4A. Apply an energy balance to a control volume at steady state, using appropriate assumptions and property data.

4B. Apply mass and energy balances for control volumes not at steady state, using appropriate assumptions and property data.

5A. Evaluate the performance of power cycles and refrigeration and heat pump cycles using corollaries of the second law.

5B. Solve problems involving Carnot cycle applications of the second law.

6. Apply entropy balances in the analysis of closed systems and control volumes.

7. Apply conservation of mass and energy, the second law, and property data to determine power cycle performance.

8A. Apply conservation energy, the second law, and property data to determine Otto, Diesel, and dual cycle performance.

8B. Apply conservation of mass and energy, the second law, and property data to determine gas turbine power cycle performance.

9. Apply conservation energy, the second law, and property data to determine the performance of vapor-compression refrigeration and heat pump cycles.

Appendix B: Example Guided Practice Assignment [21], [23]

This assignment with help you achieve the following outcome: Analyze a closed system by applying energy balances and correctly applying sign conventions for work and heat transfer.

\section{Learning Objectives}

BASIC Learning Objectives

You will be responsible for learning and demonstrating proficiency in the following objective PRIOR to group work activities.

- Apply the correct sign convention for heat and work.

\section{ADVANCED Learning Objectives}

The following objectives should be mastered by you DURING and FOLLOWING the group activities in this module through active work and practice.

- Draw a schematic for a closed system and label it with the given information.

- Apply the energy balance equation for a closed system, correctly applying SI and English units.

\section{Resources}

Read Ch. 2.3-2.5 (pages 55-72) in the textbook. Pay attention to the following:

- Sign convention for heat transfer

- Equation 2.35b (closed system energy balance equation) 
- $\quad$ Example 2.2

\section{Exercises}

These exercises can be done during or after your reading. They are intended to help you make examples of the concepts you are reading. Work these out on scratch paper, and then you will be asked to submit the results at the end.

1. Why is it incorrect to say that a system contains heat?

2. For a process in a closed system, $Q=-10 \mathrm{Btu}, \Delta E=20 \mathrm{Btu}$. Determine $W$. Is it work done by the system or on the system?

3. For a process in a closed system, $\Delta U=-500 \mathrm{Btu}, \Delta K E=0 \mathrm{Btu}, \Delta P E=50 \mathrm{Btu}$, and $W=500$ Btu. Determine $Q$. Is it heat transfer from the system or to the system?

4. What is something that you found to be difficult or unclear in the reading assignment? If you have no questions about the reading, what is something you found interesting or surprising?

\section{Submission Instructions}

Click on the "Submit Assignment" button and type or upload your answers to each of the exercises.

\section{Acknowledgment}

The author received an Online Course Development Grant from Indiana University-Purdue University Columbus to support development of the hybrid course. Additional financial support was provided by the Role of Reflection in SoTL Faculty Learning Community program through the Indiana University-Purdue University Indianapolis Center for Teaching and Learning.

\section{References}

[1] A. R. Carberry, M. Siniawski, S. A. Atwood, and H. A. Diefes-Dux, "Best Practices for Using Standards-based Grading in Engineering Courses," presented at the 2016 ASEE Annual Conference \& Exposition, New Orleans, LA, USA, Jun. 26-29, 2016.

[2] S. L. Post, "Standards-Based Grading in a Thermodynamics Course," Int. J. Eng. Pedagogy, vol. 7, no. 1, pp. 173-181, Jan. 2017.

[3] L. Nilson, Specifications Grading: Restoring Rigor, Motivating Students, and Saving Faculty Time. Sterling, VA: Stylus, 2014.

[4] J. J. Polczynski and L. E. Shirland, "Expectancy Theory and Contract Grading Combined as an Effective Motivational Force for College Students," J. Educ. Res., vol. 70, no. 5, pp. 238-241, 1977.

[5] K. Owens, "An Adventure in Standards Based Algebra," Kate S. Owens, Feb. 2, 2016. [Online]. Available: https://blogs.cofc.edu/owensks/2016/02/02/an-adventure-in-standardsbased-algebra/

[6] R. Talbert, "Specifications grading: We may have a winner," Robert Talbert, PhD, Apr. 28, 2017. [Online]. Available: http://rtalbert.org/specs-grading-iteration-winner/

[7] R. Y. Stutzman and K. H. Race, "EMRF: Everyday Rubric Grading," Math. Teach., vol. 97, no. 1, p. 34-39, Jan. 2004. 
[8] D. M. Elkins, "Grading to Learn: An Analysis of the Importance and Application of Specifications Grading in a Communication Course," Ky. J. Commun., vol. 35, no. 2, pp. 26-48, 2016.

[9] B. J. Blodgett, "Grading matters in theological education," Teach. Theol. Relig., vol. 20, no. 4, pp. 314-326, Oct. 2017.

[10] J. Ring, "ConfChem Conference on Select 2016 BCCE Presentations: Specifications Grading in the Flipped Organic Classroom," J. Chem. Educ., vol. 94, no. 12, pp. 20052006, 2017.

[11] C. Haden, P. Flikkema, T. Weller, J. Frolik, W. Verrei-Berenback, and W. Shiroma, "The Assessment Of A Hybrid On-Line/In-Class Course Developed At Multiple Universities," presented at the 2009 ASEE Annual Conference \& Exposition, Austin, TX, USA, Jun. 1417, 2009.

[12] S. Hall, C. Amelink, and S. Conn, "A Case Study Of A Thermodynamics Course: Informing Online Course Design," presented at the 2010 ASEE Annual Conference \& Exposition, Louisville, KY, USA, Jun. 20-23, 2010.

[13] L. Kinney, M. Liu, and M. A. Thornton, "Faculty and Student Perceptions of Online Learning in Engineering Education," presented at the 2012 ASEE Annual Conference \& Exposition, San Antonio, TX, USA, Jun. 10-13, 2012.

[14] S. L. Murray, J. Phelps, and K. L. Jones, "Blended Classes: Expectations vs. Reality," presented at the 2015 ASEE Annual Conference \& Exposition, Seattle, WA, USA, Jun. 1417, 2015.

[15] G. Altuger-Genc and J. Hung, "Design and Development of Online Applied Thermo-Fluid Science Courses," presented at the 2016 ASEE Annual Conference \& Exposition, New Orleans, LA, USA, Jun. 26-29, 2016.

[16] T. H. Bradley, "Evaluation of Techniques for Eliciting Online Interaction in Systems Engineering Courses," presented at the 2016 ASEE Annual Conference \& Exposition, New Orleans, LA, USA, Jun. 26-29, 2016.

[17] E. Rutz and T. R. Huston, "Comparing Student Satisfaction in Full-Term vs. Half-Term Online Course: Results of a Pilot Study," presented at the 2017 ASEE Annual Conference \& Exposition, Columbus, OH, USA, Jun. 24-28, 2017.

[18] U. D. Techera, C. Bozic, and S. Murray, "Differences in Learning Outcomes and Engagement Across Traditional, Blended, and Online Engineering Management Undergraduate Courses," presented at the 2017 ASEE Annual Conference \& Exposition, Columbus, OH, USA, Jun. 24-28, 2017.

[19] D. Yang and K. Pakala, "Building an Effective Online Thermodynamics Course for Undergraduate Engineering Students," presented at the 2017 ASEE Annual Conference \& Exposition, Columbus, OH, USA, Jun. 24-28, 2017.

[20] Canvas by Instructure [Online]. Available: https://www.canvaslms.com

[21] M. J. Moran, H. N. Shapiro, D. D. Boettner, and M. B. Bailey, Fundamentals of Engineering Thermodynamics, 8th ed. Hoboken, NJ, USA: Wiley, 2014.

[22] S. J. Lombardo, “An 'Open-ended Estimation' Design Project for Thermodynamics Students,” Chem. Eng. Educ., vol. 34, no. 2, pp. 154-157, 2000.

[23] R. Talbert, Flipped Learning: A Guide for Higher Education Faculty. Sterling, VA, USA: Stylus, 2017, pp. 134-139.

[24] LearnMechE - Educational Resources for Engineering Courses [Online]. Available: http://www.learnmeche.com 
[25] R. Talbert, Flipped Learning: A Guide for Higher Education Faculty. Sterling, VA, USA: Stylus, 2017, pp. 142-143. 